\title{
Aplikasi Metode Gradien Daya Reaktif dalam Pemisahan Kontribusi Harmonisa Konsumen dan Utilitas pada Point of Common Coupling (PCC)
}

\author{
Julius Sentosa Setiadji ${ }^{1}$, Ontoseno Penangsang ${ }^{2}$, Henie Arief Rahmawatie ${ }^{1}$ \\ ${ }^{1}$ Jurusan Teknik Elektro, Universitas Kristen Petra \\ ${ }^{2}$ Jurusan Teknik Elektro, Institut Teknologi Sepuluh Nopember \\ email: julius@petra.ac.id
}

\begin{abstract}
ABSTRAK
Gangguan harmonisa merupakan suatu fenomena di sistem daya AC. Pada mulanya penyebab harmonisa adalah ketika inti besi trafo dan mesin listrik mengalami kondisi saturasi, tetapi seiring berkembangnya teknologi modern yang ditandai dengan penggunaan komponen semikonduktor, masalah harmonisa juga semakin meningkat. Sumber harmonisa dapat berasal dari utilitas maupun konsumen, sehingga perlu dilakukan analisa pemisahan kontribusi harmonisa antara utilitas dan konsumen di PCC. Dari hasil analisa melalui grafik perubahan daya reaktif terhadap waktu $(\Delta \mathrm{Q} / \Delta \mathrm{t})$ menunjukkan bahwa grafik cenderung naik selain itu dengan analisa $\Delta \mathrm{Q} / \Delta \mathrm{t}$ diperoleh angka $0,04(\Delta \mathrm{Q} / \Delta \mathrm{t}>0)$ sehingga dapat disimpulkan bahwa utilitaslah yang mempunyai kontribusi harmonisa terbesar di PCC.
\end{abstract}

Kata kunci: harmonisa, PCC

\section{ABSTRACT}

Harmonic disturbance is a phenomenon in AC power system. In the beginning, harmonic was caused by saturated iron in transformer and electrical machine. But along expanding modern technology which marked with usage of component of semiconductor, harmonic problems also progressively increase. Harmonic source can be come from utility and customer sides, so that it is required to analyze the separation of harmonic contributions between utility and customer at the point of common coupling (PCC). Analysis result of the reactive power changes against time $(\Delta Q / \Delta t)$ shows that the graphic tends to increase and by manual analysis, the result of $\Delta Q / \Delta t$ is 0.04 , so it can be concluded that utility has the biggest harmonic contribution on PCC.

Keywords: harmonics, PCC

\section{PENDAHULUAN}

Gangguan harmonisa merupakan suatu fenomena di daya AC. Pada mulanya penyebab harmonisa adalah ketika inti besi trafo dan mesin listrik mengalami kondisi saturasi [1]. Seiring dengan pertumbuhan teknologi modern yang ditandai dengan peningkatan penggunaan komponen semikonduktor, masalahmasalah harmonisa menjadi meningkat. Yang menjadi tantangan saat ini adalah bagaimana cara membuktikan sumber harmonisa tersebut dan siapa yang bertanggung-jawab terhadap gangguan harmonisa tersebut

Beberapa metode telah ditemukan untuk mengidentifikasi sumber harmonisa, mulai dari The real power direction method $[2,3,4]$, metode berdasarkan Teorema Thevenin [5,6] dan Superposisi [7], critical impedance method [6], serta gradient daya reaktif terhadap waktu $(\Delta \mathrm{Q} / \Delta \mathrm{t})[8]$.

Catatan: Diskusi untuk makalah ini diterima sebelum tanggal 1 Juni 2008. Diskusi yang layak muat akan diterbitkan pada Jurnal Teknik Elektro volume 8, nomor 2, September 2008.

\section{POINT OF COMMON COUPLING (PCC)}

Menurut IEEE 519, PCC merupakan titik terdekat pada sisi utilitas dari pelayanan pelanggan dimana pelanggan utilitas dapat disuplai. Pengertian PCC secara praktikal yang benar adalah pada sisi primer trafo (tegangan menengah) yang melayani pelanggan, tanpa memperhatikan trafo pelanggan atau lokasi pengukuran (metering). Pada kenyataannya, tentu saja secara praktikal pengukuran dilakukan pada sisi sekunder trafo. Berikut ini adalah gambar dari PCC:

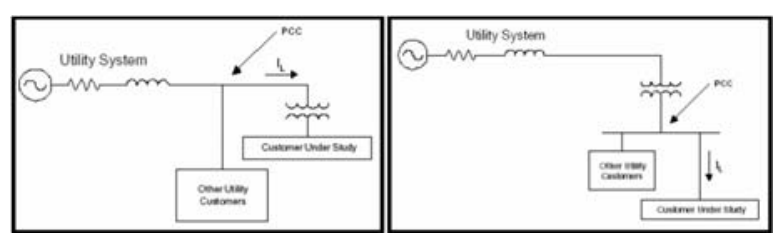

Gambar 1. Point of common coupling [9]

\section{HARMONISA}

Harmonisa merupakan suatu fenomena yang timbul akibat pengoperasian beban listrik non linier 
sehingga terbentuklah gelombang frekuensi tinggi yang merupakan kelipatan dari frekuensi fundamentalnya. Gelombang-gelombang frekwensi tinggi menumpang pada gelombang aslinya (fundamental frequency waveform) sehingga terbentuk gelombang cacat (distorted waveform) yang merupakan jumlah antara gelombang murni sesaat dengan gelombang harmoniknya.

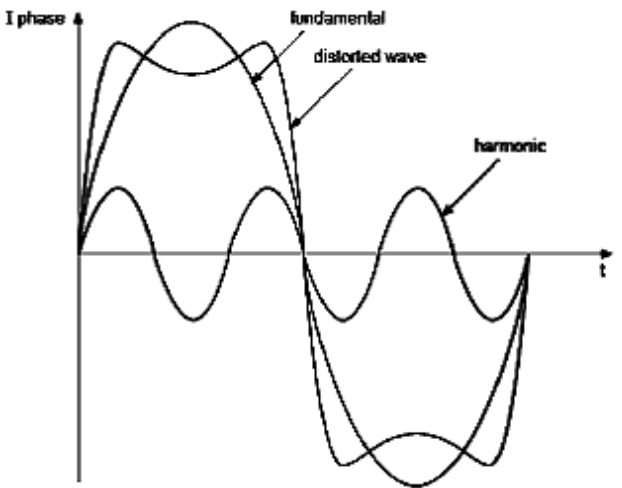

Gambar 2. Gelombang sinusoidal dan terdistorsi [10]

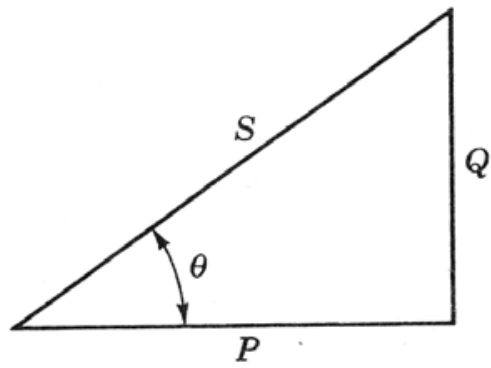

Gambar 3. Diagram vektor segitiga daya

Pada segitiga daya, ada 3 macam daya yaitu daya aktif $(\mathrm{P})$, daya reaktif $(\mathrm{Q})$ dan daya nyata $(\mathrm{S})$. Daya aktif adalah daya listrik yang dapat diubah ke bentuk energi yang lain seperti cahaya dan lain-lain. Daya reaktif adalah daya yang diperlukan untuk pembentukan medan magnet dan daya nyata adalah resultan vektor daya aktif dan reaktif.

Seperti halnya dengan segitiga daya, nilai RMS merupakan akar kuadrat dari penjumlahan fundamental $\left(\mathrm{H}_{1}\right)$ kuadrat dan harmonisa $\left(\mathrm{H}_{\mathrm{N}}\right)$ kuadrat ( NilaiRMS $=\sqrt{{H_{1}}^{2}+{H_{2}}^{2}+{H_{3}}^{2}+\ldots . .+{H_{N}}^{2}}$ )

sehingga nlai RMS dapat dianalogikan sebagai daya nyata (apparent power) sedangkan fundamental $\left(\mathrm{H}_{1}\right)$ dapat dianalogikan sebagai daya aktif dan harmonisa $\left(\mathrm{H}_{\mathrm{N}}\right)$ dapat dianalogikan sebagai daya reaktif karena sifat tidak berkontribusi pada pemakaian daya yang berdayaguna.

Apabila pada suatu sistem distribusi timbul harmonisa maka power factor sistem distribusi menjadi jelek $(<0.85)$ sehingga daya reaktif menjadi meningkat. Daya reaktif ini memerlukan kompensasi terhadap $\cos \varphi$ yang jelek tersebut berupa capasitor bank dan filter harmonik.

\section{GRADIEN DAYA REAKTIF}

Penggunaan nilai-nilai daya reaktif dalam metode gradien daya reaktif terlebih dahulu harus memperhatikan impedansi sumber harmonisa apakah induktif atau kapasitif. Metode gradien daya reaktif merupakan adaptasi dari persamaan keseimbangan energi, yaitu [8]:

$E=E_{\text {in }}-E_{\text {out }}$

dengan:

$\mathrm{E} \quad=$ Rate of change of total energy

$\mathrm{E}_{\text {in }} \quad=$ Flow of energy into the system

$\mathrm{E}_{\text {out }} \quad=$ Flow of energy out the system

Penerapan konsep keseimbangan energi pada daya reaktif pada PCC, didapatkan [8]:

$Q=Q_{\text {in }}-Q_{\text {out }}$

dengan :

$\mathrm{Q} \quad=$ Rate of change of total reactive power

Qin = Flow of reactive power into the system

Qout $=$ Flow of reactive power out the system

Persamaan 2 dapat dituliskan ulang sebagai berikut [8]:

$\frac{\Delta Q}{\Delta t}=\frac{Q_{\text {in }}-Q_{\text {out }}}{\Delta t}$

Pada gambar 3 diasumsikan bahwa arah positif daya reaktif adalah dari utilitas ke konsumen.

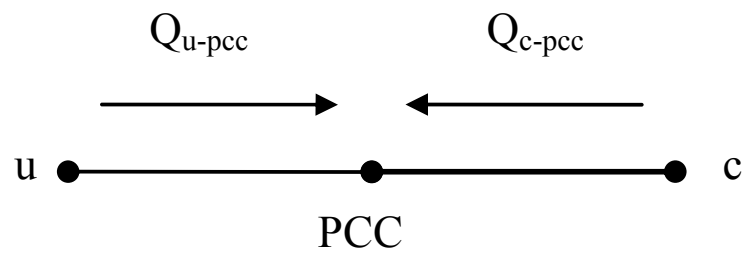

Gambar 4. Arah posistif daya reaktif [8]

keterangan:

$\mathrm{Q}_{\mathrm{u}-\mathrm{pcc}}$ : Daya reaktif dari ulititas ke PCC

$\mathrm{Q}_{\mathrm{c}-\mathrm{pcc}}$ : Daya reaktif dari konsumen ke PCC

U : Utilitas

C : Konsumen

Pada PCC, tingkat perubahan daya reaktif adalah [8]:

$\frac{\Delta Q_{p c c}}{\Delta t}=\frac{Q_{u-p c c}-Q_{c-p c c}}{\Delta t}$

Jika $\mathrm{Q}_{\mathrm{u}-\mathrm{pcc}}>\mathrm{Q}_{\mathrm{c} \text {-pcc }}$ maka $\Delta \mathrm{Q}_{\mathrm{pcc}} / \Delta \mathrm{t}>0$ sehingga sumber utama harmonisa adalah utilitas sedangkan jika $\mathrm{Q}_{\mathrm{u}-\mathrm{pcc}}<\mathrm{Q}_{\mathrm{c} \text {-pcc }}$ maka $\Delta \mathrm{Q}_{\mathrm{pcc}} / \Delta \mathrm{t}<0$ sehingga sumber utama harmonisa adalah konsumen.

Dari rumus tersebut maka untuk menghitung daya reaktif pada PCC digunakan rumus [8]: 
$Q_{p c c}=\operatorname{Im}\left(V_{p c c} * I_{p c c}^{*}\right.$

dengan:

$\mathrm{Q}_{p c c}$ : Daya reaktif pada PCC

$\mathrm{V}_{p c c}$ : tegangan harmonisa yang diukur pada PCC

$I_{p c c}$ : arus harmonisa yang diukur pada PCC

Hipotesis untuk metode gradient daya reaktif dapat disederhanakan sebagai berikut:

- Jika $\Delta \mathrm{Q} / \Delta \mathrm{t}>0$, utilitas sebagai sumber utama harmonisa

- Jika $\Delta \mathrm{Q} / \Delta \mathrm{t}<0$, konsumen sebagai sumber utama harmonisa

\section{PENGUMPULAN DATA}

Penelitian dilakukan di PCC salah satu Gardu Induk yang menyuplai industri peleburan baja dimana peralatan pabrik yang digunakan antara lain adalah electric arc furnace (EAF). EAF menghasilkan harmonisa yang cukup besar pada sistem distribusi.

Spesifikasi Trafo di sisi utilitas:

$\begin{array}{ll}\text { Tipe } & : \text { Outdoor } \\ \text { Daya } & : 60.000 \mathrm{kVA} \\ \text { Tegangan Kerja } & : 150 \mathrm{kV} / / 20 \mathrm{kV} \\ \text { Arus } & : 1,7-230,9 \mathrm{~A} \\ \text { Hubungan } & : \text { YNyn0 } \\ \text { Impedansi } & : 12,8 \% \\ \text { Phasa } & : 3 \\ \text { Frekwensi } & : 50 \mathrm{~Hz} \\ \text { Tipe Pendinginan } & : \text { ONAN/ONAF }\end{array}$

Dengan melakukan pengukuran dan perekaman data di titik PCC (pada sekunder CT dan PT di panel incoming $20 \mathrm{kV}$ - sisi sekunder transformator) maka diperoleh data daya reaktif (Q), arus harmonisa dan tegangan harmonisa (Tabel 3). Setelah dilakukan pengukuran ternyata harmonisa ke 7 merupakan harmonisa yang paling dominan, sehingga data arus harmonisa $\left(\mathrm{I}_{\mathrm{h} 7}\right)$ dan tegangan harmonisa ke $7\left(\mathrm{~V}_{\mathrm{h} 7}\right)$ yang digunakan untuk analisa.

Tabel 3. Daya reaktif \& rata-rata ITHD

\begin{tabular}{cccc}
\hline $\begin{array}{c}\text { Waktu } \\
(\mathbf{t})\end{array}$ & $\begin{array}{c}\text { Daya Reaktif } \\
(\text { Var) }\end{array}$ & $\begin{array}{c}\mathbf{I}_{\mathbf{h} 7} \\
(\mathbf{A})\end{array}$ & $\begin{array}{c}\mathbf{V}_{\mathbf{h}} \\
(\mathbf{V})\end{array}$ \\
\hline $15: 15$ & 309 & 84 & 62 \\
$15: 20$ & 342 & 84 & 74 \\
$15: 24$ & 267 & 60 & 54 \\
$15: 27$ & 258 & 60 & 56 \\
$15: 31$ & 336 & 84 & 72 \\
$15: 34$ & 264 & 60 & 52 \\
$15: 42$ & 303 & 72 & 56 \\
$15: 47$ & 405 & 84 & 68 \\
$15: 52$ & 315 & 60 & 48 \\
$15: 55$ & 327 & 72 & 64 \\
$16: 00$ & 405 & 84 & 66 \\
\hline
\end{tabular}

\section{Analisa Sumber Harmonisa Berdasarkan Grafik}

Analisa sumber harmonisa dapat dilakukan dengan melihat daya reaktifnya. Hal ini dikarenakan jika pada suatu sistem distribusi terdapat harmonisa maka harmonisa akan membuat PF (power factor) dan DPF (displacement power factor) pada sistem tersebut menjadi lebih rendah dari 0,85 . Pada analisa dengan menggunakan metode gradien daya reaktif, sumber harmonisa terbesar pada PCC dapat diketahui dengan membuat grafik dengan menggunakan data pada Tabel 3 .

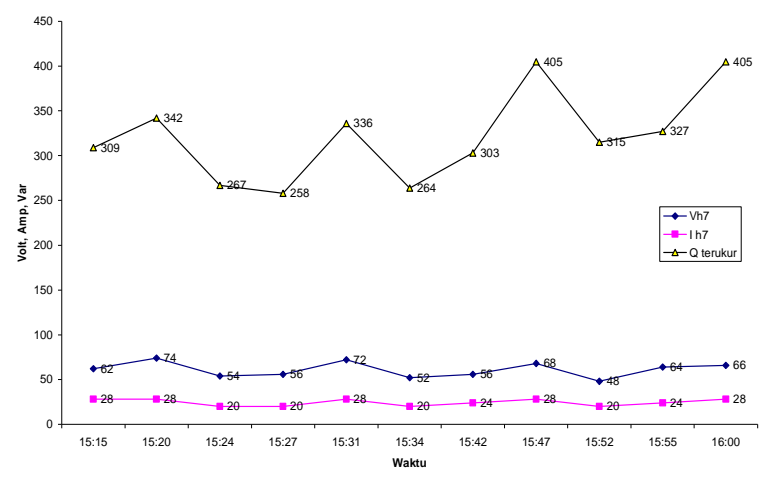

Gambar 5. Grafik hubungan antara $\mathrm{V}_{\mathrm{h} 7}, \mathrm{I}_{\mathrm{h} 7}$ dan Q

Pada Gambar 5 terlihat bahwa besarnya daya reaktif (Q) mengikuti besarnya arus dan tegangan harmonisa. Semakin besar arus dan atau tegangan harmonisa maka semakin besar pula daya reaktifnya, demikian sebaliknya. Hal ini membuktikan bahwa besarnya daya reaktif dapat digunakan untuk menganalisa sumber harmonisa.

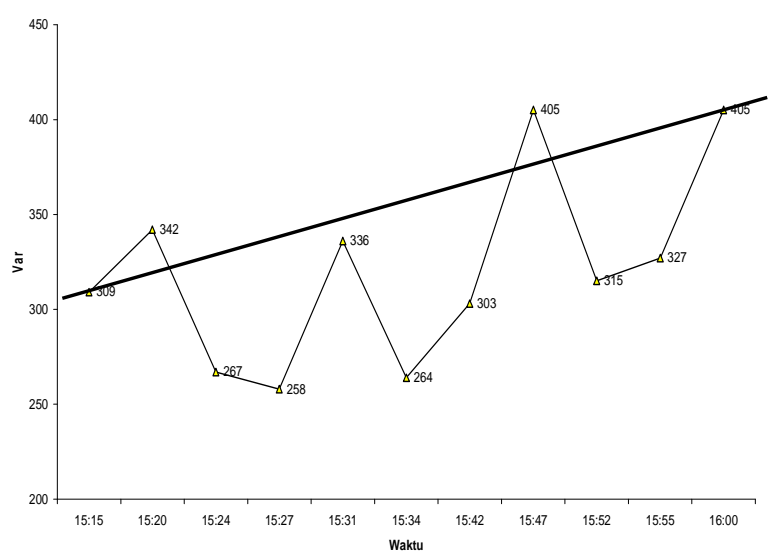

Gambar 6. Grafik daya reaktif terhadap waktu

Dari Gambar 6 terlihat bahwa kecenderungan grafik daya reaktif terhadap waktu mengalami kenaikan. Berdasarkan konsep metode gradien daya reaktif disebutkan bahwa jika $\Delta \mathrm{Q} / \Delta \mathrm{t}>0$ atau arah positif maka dapat disimpulkan bahwa sumber harmonisa terbesar adalah dari sisi utilitas 
Dalam menganalisa sumber harmonisa, metode Gradient Daya Reaktif membutuhkan data lebih dari satu kali pengukuran untuk mengetahui kecenderungan kenaikan atau penurunan daya reaktif dan arus \& tegangan harmonisa sehingga dibutuhkan alat ukur yang dapat merekam data pada suatu kurun waktu tertentu.

\section{Analisa Sumber Harmonisa Berdasarkan Perhitungan}

Selain menggunakan grafik, analisa metode gradien daya reaktif dapat juga dilakukan dengan menggunakan analisa perhitungan. Dengan menggunakan tabel 3, dicari nilai $\Delta \mathrm{Q} / \Delta \mathrm{t}$ apakah lebih besar dari nol atau kurang dari nol

$$
\begin{aligned}
\Delta \mathrm{Q} & =\mathrm{Q}_{\text {akhir }}-\mathrm{Q}_{\text {awal }} \\
& =405-309=96 \mathrm{Var} \\
\Delta \mathrm{t} & =\mathrm{t}_{\text {akhir }}-\mathrm{t}_{\text {awal }} \\
& =16: 00-15: 15=2700 \text { detik }
\end{aligned}
$$$$
\frac{\Delta Q}{\Delta t}=\frac{96}{2700}
$$$$
=0,04>0
$$

Dari hasil perhitungan di atas terlihat bahwa $\Delta \mathrm{Q} / \Delta \mathrm{t}>0$ maka berdasarkan konsep metode gradien daya reaktif dapat disimpulkan bahwa sumber harmonisa terbesar adalah dari sisi utilitas.

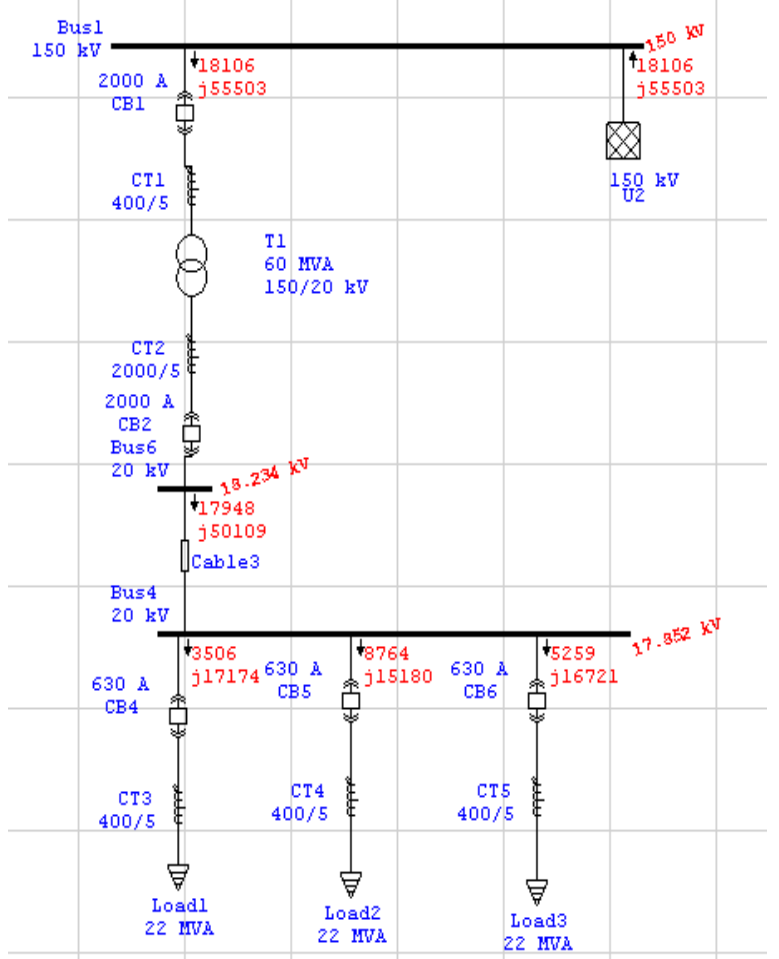

Gambar 7. Simulasi dengan ETAP

\section{Analisa Sumber Harmonisa Berdasarkan Aliran Daya Reaktif}

Berdasarkan data-data pengukuran dan spesifikasi transformator, maka dapat dibuat bentuk pemodelannya dengan menggunakan ETAP dapat dilihat pada Gambar 7 menunjukkan hasil run load flow dengan software ETAP. Pada bus 6 terlihat daya reaktif yang masuk ke PCC (bus 4) adalah sebesar 50109 kVar. Sedangkan total daya reaktif yang keluar dari PCC yang masuk ke beban-beban adalah sebesar 49675 kVar (17174+15180+16721). Berdasarkan konsep metode gradien daya reaktif disebutkan bahwa jika $\mathrm{Q}_{\mathrm{u}-\mathrm{pcc}}>\mathrm{Q}_{\mathrm{c} \text {-pcc }}$ dan $\Delta \mathrm{Q}_{\mathrm{pcc}} / \Delta \mathrm{t}>0$ maka dapat disimpulkan bahwa sumber harmonisa terbesar adalah dari sisi utilitas

\section{KESIMPULAN}

Berdasarkan analisa sumber harmonisa berdasarkan grafik, perhitungan dan aliran daya reaktif, metode gradient daya reaktif menunjukkan bahwa sumber harmonisa terbesar adalah dari sisi utilitas. Karena sumber harmonisa terbesar dari utilitas maka pada sisi utiltas perlu dipasang filter harmonisa agar harmonisa tersebut tidak menyebar ke seluruh sistem distribusi.

\section{DAFTAR PUSTAKA}

[1] Teshome, "Harmonic Source and Type Identification in a Radial Distribution System (Presented Conference Paper style)", presented at the IEEE 1991 Industry Applications Society annual Meeting, Dearboran, Michigan, September 28-October 4, 1991, Paper No. 32025.

[2] W. Xu, X. Liu and Y. Liu, "An Investigation on the validity of power-direction method for harmonic source detection", IEEE Trans. Power Delivery, vol. 18, pp. 214-218, January 2003.

[3] W. Xu and Y. Liu, "A method for determining customer and utility harmonic contributions at the point of common coupling", IEEE Trans. Power Delivery, vol. 15, pp. 804-811, Apr. 2000.

[4] M. Tsukamoto, I. Kouda, Y. Natsuda, Y Minowa and S. Nishimura, "Advanced method to identify harmonics characteristic between utility grid and harmonic current sources", presented at the $8^{\text {th }}$ Int. Conference on harmonic and quality of power, Oct. 14-16, 1998, pp. 419-425. 
[5] Robert and T. Deflandre, "Guide for assessing the network harmonic impedance", CIRED 97, June 2-5, 1997 Conf. Publication No. 438, pp. 2.3.1-2.3.10.

[6] Li, W. Xu and T. Tayjansanant, "A critical impedance based method for identifying harmonic sources", Available: http://www.ee. ealberta.ca/ wxu/papers/PQ-ReactivePower Distribution.pdf.

[7] M. Tsukamoto, A. Ogawa, Y. Natsuda, Y, Minowa and S. Nishiura, "Advanced Technology to identify harmonics characteristics and results of measuring", in Ninth Proc. Harmonics and Quality of Power, 2000, vol. 1. pp. 341346.

[8] Hamzah, Noraliza., Azah Mohamad and Aini Hussain, "A New Method for Separating Utility and Customer Harmonic Contribution at The Point of Common Coupling" Electricity Supply Industry in Transition: Issues and Prospect for Asia, January 14-16, 2004.
[9] Carnovale, Daniel J. and Thomas M. Blooming. Application of IEEE Std 519-1992 Harmonics Limits. North Carolina. October 21, 2006.

[10] Noel, Qillon and Pierre, Roccia. Harmonic in Industrial Network. 1994. Merlin Gerin, 3 September 2008.

$<\mathrm{http} / / /$ www.cn.co.kr/enuser/power/powerpdf/e ct152.pdf $>$.

[11] Arrilaga, Jos and Watson, Neville. Power System Harmonics. Chicester : John Walley and Sons, 2003.

[12] Sankaran, C. Power Quality. Florida : CRC Press. 2002.

[13] Mazur, Glen. Power Measurement and Troubleshooting. Illinois: Fluke Production, 1998.

[14] Anders, G.J., Conlon,M.F., Lawrence,W.B., Mielczarski, W., H. Khalsa dan G. Michalik. Quality of Electricity Supply and Management of Network Losses. Melbourne: Puma Press, 1997. 